Children and Youth

\title{
Looking for a pattern: Error analysis as a diagnostic assessment for making instructional decisions to promote academic success
}

\section{Lucia M. Tabacu, Silvana Maria Watson, Laura C. Chezar, Robert Gable, Célia R. Oliveira \& João Lopes}

To cite this article: Lucia M. Tabacu, Silvana Maria Watson, Laura C. Chezar, Robert Gable, Célia R. Oliveira \& João Lopes (2020) Looking for a pattern: Error analysis as a diagnostic assessment for making instructional decisions to promote academic success, Preventing School Failure:

Alternative Education for Children and Youth, 65:1, 58-69, DOI: 10.1080/1045988X.2020.1818180

To link to this article: https://doi.org/10.1080/1045988X.2020.1818180

\section{曲 Published online: 15 Sep 2020.}

Submit your article to this journal $\pi$

Џ Article views: 160

Q View related articles $\sqsubset$

View Crossmark data ¿ 


\title{
Looking for a pattern: Error analysis as a diagnostic assessment for making instructional decisions to promote academic success
}

\author{
Lucia M. Tabacu a, Silvana Maria Watson ${ }^{a}$, Laura C. Chezar ${ }^{a}$, Robert Gable ${ }^{a}$, Célia R. Oliveira ${ }^{b}$, and \\ João Lopes ${ }^{c}$
}

${ }^{a}$ Old Dominion University, Norfolk, VA, USA; ${ }^{b}$ Universidade Lusófona de Humanidades e Tecnologias Observatório de Políticas de Educação e de Contextos Educativos, Porto, Portugal; 'Universidade do Minho, Braga, Portugal

\begin{abstract}
We examined the type of errors on multiplication and division computation problems of 326 rising fifth graders enrolled in four elementary schools in Northern Portugal. We further examined whether there was a difference in the number of errors across age and whether there was an association between students' performance on number knowledge and multiplication and division computation problems. Error analysis of students' responses indicated that miscalculation and no attempt to solve the problem were the two most frequent error types. We found that older students made more errors compared to younger students. We argue that knowledge of individual student error types is critical to making sound instructional decisions. Based on the results of the present study, we discuss implications for future research and classroom practice.
\end{abstract}

\section{KEYWORDS}

Assessment; division; error analysis; instruction; multiplication
By all accounts, math plays a significant role in a student's academic success. One aspect of math that is critical to that success is computation which consists of conceptual and procedural knowledge and skills. Conceptual knowledge refers to acquisition and understanding of concepts and the relationships among concepts, whereas procedural knowledge involves action sequences, facts, and procedures for solving problems (Arslan, 2010). Computation requires students to select and apply a specific sequence of steps related to arithmetic operations to solve math problems. Computation applies not only to whole numbers, but also to decimals, fractions, percentages, ratios, and proportions. However, computation of whole numbers is the basis for the acquisition of more complex skills, such as problem solving and fractions (Ashlock, 2010).

According to the National Mathematics Advisory Council (2008), students need to first acquire conceptual and procedural knowledge of computation problems to support learning of more advanced math skills. In other words, basic math computation in addition, subtraction, multiplication, and division must be mastered before a student can progress through more complex math skills (Geary, 2011). For example, the speed and accuracy required to solve single and multidigit computation problems strongly affect algebra achievement (Tolar et al., 2009). Indeed, there is compelling evidence that the acquisition of conceptual and procedural knowledge and skills is essential for students to advance in math (e.g., learn algebra). For that reason, it is critical to gain an understanding of students' errors when solving computation problems that negatively impact their academic achievement (Ashlock, 2010).
Over the last several decades researchers have examined students' errors in basic math computation with most studies being conducted in the $60 \mathrm{~s}, 70 \mathrm{~s}$, and $80 \mathrm{~s}$. A review of those studies reveals that researchers have used different classification systems to categorize the types of errors made by students when completing computation problems. For example, Roberts (1968) classified students' math computation errors in four categories: wrong operation, obvious computation error, defective algorithm, and random errors. Engelhardt (1977) expanded this categorization to include eight categories, namely: basic facts, grouping, inappropriate inversion, incorrect operation, defective algorithm, identity, and concept of zero; whereas, Stefanich and Rokusek (1992) used six categories: regrouping, place value, zero or identity concept, basic facts, faulty or incomplete procedure, and remainder.

One finding of the above studies is the consistent cooccurrence of the same math computation error across the four math operations (e.g., failure to regroup). This suggests that teachers should analyze the students' strategy or lack of strategy in math computation to identify an effective intervention plan to promote students' academic achievement (Roberts, 1968). Another finding relates to the most common types of students' errors in completing computation problems. Specifically, the most common errors include: defective or incorrect algorithm (e.g., $303 \times 25=6015$ $[5 \times 3=15 ; 0 \times 2=0 ; 2 \times 3=6])$ reported by Brown and Burton (1978) and Engelhardt (1977); subtracting larger positive numbers from smaller positive numbers (e.g., $42-16=34$ ) depicted by Cebulski (1984), and faulty or 
incomplete procedure, regrouping, and zero or identity concept (e.g., 6: $2=30$ ) described by Stefanich and Rokusek (1992).

Several researchers have continued to examine students' errors in basic math computation (Nelson \& Powell, 2018). However, the focus has shifted from categorizing the types of errors to examining the relation between the type of error and the potential contributing factors (Nelson \& Powell, 2018; Traff \& Samuelson, 2013) and the ability of in-service and preservice teachers to identify students' error patterns (Cooper, 2009; Riccomini, 2005). One potential factor that contributes to students' systematic errors and hinders their acquisition of basic math computation, such as computing whole numbers, is faulty number knowledge (Namkung \& Fuchs, 2012). For example, consider multiplying $27 \times 3$. First, the student would have to acquire a linear representation of the number system and understand that the 2 represents 2 tens (or 20) and the 7 represents 7 ones. Then, the student would have to know the multiplication fact for $7 \times 3$, and when multiplying 7 and 3 , he or she will write the 1 below and regroup the 2 to the next column and understand the relationships between the digits and the number.

Skwarchuk and Betts (2006) analyzed the errors in number production for 96 students in the first, third, fifth, and seventh grade across three categories (i.e., prerequisite linguistic, vocabulary, and compound construct). Data indicated that prerequisite linguistic conventions (i.e., understanding the numeral to number word translation process, such as five, four, three for 543, four and six for 46, and fifteen eight, thirty-two three for 158,323 ) are critical to start and sustain number production. Not surprisingly, difficulties in that understanding lead to student errors. Additionally, vocabulary errors occurred in all grades and compound construction (i.e., syntactic structure to organize numbers) were more frequent in grades three and beyond.

A second potential factor contributing to student errors in math computation relates to arithmetic accuracy and fluency. Arithmetic accuracy and fluency require conceptual knowledge and understanding, flexible thinking, precision, and speed in completing math problems both by using the four basic operations and by selecting and applying specific strategies (Gojak, 2012). Despite the common instructional emphasis on promoting accuracy and fluency in computing whole numbers, many students struggle to reach mastery (Zhang et al., 2014) which, in turn, negatively influences their performance.

To promote mastery and fluency of math computation, experts recommend diagnostic analysis of errors as an important assessment method to interpret, diagnose, and remediate students' misconceptions by using appropriate and efficient instructional strategies (Sapire et al., 2016). Diagnostic analysis of errors is an assessment approach that allows a teacher to determine whether a student is making random versus consistent errors and, in turn, to identify possible error patterns (Callejo \& Zapatera, 2017). Making errors at the early skill-acquisition stage is common to factors, such as novelty and complexity of the targeted skill. However, systematic and persistent errors may indicate error patterns that signal the presence of deficits in math computation, including faulty reasoning and lack of conceptual and procedural knowledge (Ashlock, 2010).

For example, when a student persistently subtracts a positive larger number from a positive smaller number (e.g., $23-14=11)$, it may suggest that the student does not understand the concept of place value. A student's incomplete knowledge of a concept may lead to repeated and systematic errors revealing error patterns. These error patterns often expose a student's misunderstanding of math computation that teachers must be able to recognize and interpret (Callejo \& Zapatera, 2017). If instruction for this student does not focus specifically on the concepts of place value and regrouping, the student will continue to make the same error in subtraction and related math operations (e.g., division) that require the comprehension and application of the concepts listed previously. When error patterns persist because they are not addressed, they will have an enduring impact on student progress in math (Geary, 2011).

Thus, the purpose of this study was to extend the previous research on error analysis in basic math computation in several ways. First, we conducted an in-depth analysis of the types of errors on multiplication and division problems by examining students' errors when computing both whole numbers and numbers containing decimals. Most of the studies examining students' errors were conducted several decades ago and focused mostly on computation of whole numbers. Second, we added to the coding systems previously used by researchers. Third, we examined the correlation between math computation and number knowledge (e.g., symbolic number sense and magnitude) based on the existing empirical evidence that links the number knowledge and processing to subsequent math achievement (Geary, 2011). Findings of previous studies indicated that students with math difficulties had weak number sense (Jordan et al., 2003, 2010); however, the correlation between number knowledge and error types in multiplication and division has not been previously examined. Accordingly, our research questions were

1. What are the most prevalent types of errors on single and multidigit multiplication and division problems with and without decimals among rising fifth-grade Portuguese students?

2. Are there any correlations between students' performance on number knowledge and types of errors on single and multidigit multiplication problems with and without decimals among rising fifth-grade Portuguese students?

3. Are there any correlations between students' performance on number knowledge and types of errors on single and multidigit division problems consisting with and without decimals among rising fifth-grade Portuguese students?

\section{Method}

\section{Participants and setting}

Participants were 326 rising fifth-grade students (i.e., students who completed the fourth grade at the beginning of 
Table 1 . Number of students by gender and age across schools.

\begin{tabular}{|c|c|c|c|c|c|c|c|c|}
\hline \multirow[b]{2}{*}{ School } & \multirow[b]{2}{*}{ Gender } & \multicolumn{5}{|c|}{ Age } & \multicolumn{2}{|c|}{ Total by: } \\
\hline & & 9 & 10 & 11 & 12 & 13 & Age & School \\
\hline \multirow[t]{2}{*}{ A } & Male & 14 & 61 & 8 & 1 & 0 & 84 & 179 \\
\hline & Female & 14 & 77 & 4 & 0 & 0 & 95 & \\
\hline \multirow[t]{2}{*}{ B } & Male & 5 & 9 & 2 & 3 & 0 & 19 & 36 \\
\hline & Female & 2 & 12 & 3 & 0 & 0 & 17 & \\
\hline \multirow[t]{2}{*}{ C } & Male & 1 & 9 & 3 & 0 & 0 & 13 & 44 \\
\hline & Female & 9 & 15 & 6 & 1 & 0 & 31 & \\
\hline \multirow[t]{2}{*}{ D } & Male & 9 & 28 & 6 & 1 & 1 & 45 & 67 \\
\hline & Female & 4 & 15 & 2 & 1 & 0 & 22 & \\
\hline Total & & 58 & 226 & 34 & 7 & 1 & 326 & \\
\hline
\end{tabular}

the study) from four elementary schools in Northern Portugal: 179 students in School A; 36 students in School B; 44 students in School C; and 67 students in School D. Of the 326 students, $51 \%(n=165)$ were females and $49 \%$ ( $n=161)$ were males. Although the average age range of rising fifth graders is 10 , the students ranged in age from nine to thirteen years old. The majority of the students came from families with a low socioeconomic status. All students received instruction in the general education curriculum. See Table 1 for information about the participants and schools.

\section{Measures}

Students completed a written test of math computation developed by Lopes and Bueno (2014) who assessed the reliability and validity of the test prior to our data collection. Based on the Rasch model of the item response theory, a psychometric analysis showed that the items covered the full extension of the participants' skills. The assessment instrument has a total of 46 items divided into three main sections: number knowledge, computation, and problem solving. In this article, we report data on the total score on number knowledge and the total score and most frequent types of errors on multiplication and division computation problems for students who had completed the fourth grade. The number knowledge segment of the test consisted of three domains (i.e., writing numbers, number magnitude, and decomposing numbers) and included 18 items. The maximum score possible on the number knowledge segment was 18. The assessment instrument is closely aligned with the Portuguese math curriculum taught from first through fourth grade. The multiplication and division segments of the test included 10 items: five items for multiplication and five items for division. The items involved single (e.g., $9 \times 736$; 256: 8), multidigit (e.g., $46 \times 75 ; 338: 26$ ), and decimals (e.g., $15,7 \times 3,54 ; 15: 1,25)$ types of problems. The maximum score possible both on multiplication and on division problems was 5 .

\section{Procedures}

\section{Assessment administration}

We administered the assessment within the context of a larger study during the first two weeks of the school year. Thus, the participants had completed the fourth grade and were starting the fifth grade. Prior to administering the test, the teachers met with two of the researchers who provided oral and written directions on how to administer the assessment. The researchers provided the written directions in a package containing the assessment instrument and step-bystep instructions on how to administer the test. Two of the researchers collected the tests administered by teachers and completed by students.

During the regularly-scheduled math instruction, the classroom teacher presented the assessment and asked the students to complete it. The teachers did not provide students instruction or any other type of assistance on how to solve the items included in the test. Whole-class assessment occurred in the students' classrooms. All students completed the test during the allotted class time. Once the students finished answering the exam's questions, the teachers placed the students' completed tests in the original envelope provided by the researchers and returned the exams to the researchers in their original packages.

\section{Response and error coding}

Two researchers analyzed the assessment results in three phases. In the first phase, the researchers identified correct and incorrect responses. A correct response was defined as having all algorithms of a product or quotient accurate. A correct response for the number knowledge problems was defined as having all numbers displayed according to their place value and the vocabulary words correctly named and organized. A correct response received a score of 1 . An incorrect response was defined as having any erroneous algorithm of a product or quotient. The researchers coded errors for number knowledge problems when an inadequacy in the number word translation process occurred, the students used the vocabulary incorrectly, omitted a word, or organized the words incorrectly (e.g., one thousand hundred for 100,000.00). An incorrect response received a score of 0 . We assigned a score of 0 regardless of the number of errors made by a student on the same number knowledge or computation problem; however, we coded all errors.

In the second phase, the two researchers reviewed each incorrect response and coded the types of errors (e.g. $\mathrm{MC}=$ miscalculation; $\mathrm{FR}=$ failure to regroup; $\mathrm{PL}=$ prerequisite linguistic). Researchers created a list consisting of different types of errors and their definition based on a review of published studies (Engelhardt, 1977; Skwarchuk \& Betts, 2006; Traff \& Samuelson, 2013). When the researchers identified an error that was not included in the original list, they met to discuss the type of error committed by the students and expanded the original list. Tables $2 \mathrm{a}$ and $2 \mathrm{~b}$ display the types of errors made by students on the assessment items related to multiplication and division, respectively on items related to number knowledge problems.

In the third phase, researchers reexamined all assessments using the new coding system. The researchers also observed that a student could have more than one error on the same calculation problem. For example, the multiplication problem $524 \times 7=3,567$ has two types of errors. The first error is a MC because $7 \times 4$ is 28 and not 27 and $7 \times 5=35$. The second type of error is FR. Specifically, the student did not 
Table 2a. Coding of types of errors related to multiplication and division calculations.

\begin{tabular}{ll}
\hline Abbreviation & \\
\hline MC & Miscalculation \\
WO & Wrong operation \\
CZ & Concept of zero \\
FR & Failure to regroup \\
RAEa & Random errors: decimals \\
RAEb & Random errors: copying numbers incorrectly \\
RAEC & Random errors: incorrect answer without explanation \\
RAEd & Random errors: omission (began to solve the problem, but did not complete it) \\
RAEe & Random errors: procedure error \\
NA & No attempt to solve the problem \\
\hline
\end{tabular}

Table 2b. Coding of types of errors related to number knowledge.

\begin{tabular}{|c|c|c|}
\hline Abbreviation & Type of error & Example \\
\hline$\overline{\mathrm{PL}}$ & $\begin{array}{l}\text { Prerequisite } \\
\text { Linguistic }\end{array}$ & $\begin{array}{l}\text { Read digits according to value (e.g., } 378=\text { three, seven, eight) } \\
\text { Added or omitted number words in relation to the number of digits in the } \\
\text { numeral (e.g., } 200=\text { two hundred) } \\
\text { Interpreted zero incorrectly by saying it (e.g., } 305=\text { three hundred zero five) } \\
\text { Did not read the digits in order of magnitude starting from left (e.g., } 46 \\
\text { sixty-four) } \\
\text { Did not organize the digits conventionally in groups of three, using comma or } \\
\text { space indicating the appropriate grouping (e.g., } 132,125=\text { thirteen two, } \\
\text { twelve five) }\end{array}$ \\
\hline V & Vocabulary & $\begin{array}{l}\text { No knowledge of appropriate vocabulary (e.g., } 100,000=\text { one hundred million) } \\
\text { Omission of appropriate vocabulary (e.g., 3,500 = three, five hundred = The } \\
\text { word thousand is missing) }\end{array}$ \\
\hline $\mathrm{CC}$ & $\begin{array}{l}\text { Compound } \\
\text { Construction }\end{array}$ & $\begin{array}{l}\text { Vocabulary words are cited, but not organized correctly - omission or } \\
\text { substitution } \\
\text { No consistent syntactic structure (e.g., } 100,000=\text { one thousand hundred) }\end{array}$ \\
\hline
\end{tabular}

add 1 to regroup and the answer should be 36 . The correct product for this multiplication calculation task is 3,668. Therefore, the researchers recorded both types of errors when coding the answer for the multiplication problem for this student and assigned a code of 0 for incorrect response.

At the end of the third phase, a third researcher conducted a point-by-point agreement on error types for $65 \%(n=213)$ of randomly-selected assessments by independently coding them using the final coding list. We calculated interobserver agreement (IOA) by dividing the number of agreements by agreements plus disagreements $(\mathrm{A} /[\mathrm{A}+\mathrm{D}])$ and multiplying the quotient by 100 . We recorded an agreement when both the primary observer and the reliability coder recorded the same type of error when coding a student's response. A disagreement was recorded when the primary observer and the reliability coder recorded different types of errors when coding a student's response. The mean IOA was $98 \%$. When a disagreement occurred, a third researcher re-graded the test and identified the error types to resolve the issue.

\section{Data analysis}

First, we used frequencies to describe students' demographic information, the type of errors made by students when solving multiplication and division computation problems, and the distribution of errors across age. Second, we computed a Pearson correlation to determine whether an association existed between students' number knowledge score and each type of error identified on the multiplication and division computation problems. We reported only those correlations that had significant $p$-values when testing the null hypothesis (i.e., the true correlation is equal to zero). The statistical analyses were conducted using $\mathrm{R}$ software ( $\mathrm{R}$ Core Team, 2017). Because of the wide spread of ages among the participants, we also conducted a nonparametric Kruskal-Wallis rank sum test (Higgins, 2004) to determine whether a statistically significant difference existed between the number of errors on multiplication and division computation problems and age. If the Kruskal-Wallis rank sum test yielded a statistically-significant difference between age groups, we conducted a Dunn post-hoc analysis (Dunn, 1964) to identify which age groups were different. We adjusted the $p$-values for the Dunn post-hoc analysis with the Benjamini-Hochberg method (Benjamini \& Hochberg, 1995) as implemented in the R package Fisheries Stock Analysis (Ogle et al., 2018).

\section{Results}

\section{The most prevalent error types on multiplication and division problems}

\section{Multiplication}

There was a total of 810 multiplication errors. Frequency analyses data showed that the most common type of error for multiplication was MC. MC represented 33.4\% (271 of 810 ) of the multiplication errors among the 326 Portuguese rising fifth graders. The second most prevalent type of error, $18.76 \%$ (152 of 810$)$ of the multiplication errors, was unsolved multiplication computation problems. Students' answers were marked as incorrect because the problem was unanswered and, thus, indicating that there was no attempt to solve it. Those error types were coded as 'No Attempt' (NA) error. The third most frequent type of multiplication error was related to decimals (i.e., RAEa). One hundred 
fifty-one (18.64\%) errors were considered errors related to multiplication of decimals. Furthermore, $13.95 \%$ (113 of 810 ) of the multiplication errors consisted of incorrect answers that could not be explained or justified (e.g., $24 \times 19=1249$ ). Those error types without explanation were coded as RAEc. Table 3 displays the total number of types of errors for multiplication and division computation problems.

\section{Division}

There were 1032 error types in the division segment of the assessment. The 484 (46.89\%) errors coded NA represented the most prevalent type of error on division computation problems. Incorrect answers without explanation type of error (i.e., RAEc) was the second most frequent error type representing $41.47 \%$ (428 of 1032) of the division computation errors. Wrong answers because of erroneous procedural knowledge (i.e., RAEe) comprised 9.5\% (99 of 1032) of the division computation errors represented the third most recurring error type (see Table 3 ).

\section{Correlations between number knowledge and type of errors on multiplication and division computation problems}

\section{Multiplication}

Data revealed that the correlation of the students' number knowledge scores with MC errors was $-0.186(p<.001)$,

Table 3. Number of errors by type for all students for multiplication and division calculation problems.

\begin{tabular}{lcc}
\hline & \multicolumn{2}{c}{ Problem } \\
\cline { 2 - 3 } Error type & Multiplication & Division \\
\hline MC & 271 & 15 \\
FR & 90 & 0 \\
CZ & 5 & 0 \\
RAEa & 151 & 3 \\
RAEb & 1 & 0 \\
RAEC & 113 & 428 \\
RAEd & 12 & 0 \\
RAEe & 15 & 99 \\
WO & 0 & 3 \\
NA & 152 & 484 \\
\hline
\end{tabular}

Note: $M C=$ miscalculation; $F R=$ failure to regroup; $C Z=$ concept of zero; $\mathrm{RAEa}=$ random errors: decimals; $\mathrm{RAEb}=$ Random errors: copying numbers incorrectly; RAEC = random errors: incorrect answer without explanation; RAEd = Random errors: omission (began to solve the problem, but did not complete it); $\mathrm{RAEe}=$ random errors: procedure error; $\mathrm{WO}=$ wrong operation; $\mathrm{NA}=$ no attempt to solve. with CZ errors was $-0.144(p<.01)$, with RAEc errors was $-0.147(p<.01)$, with RAEe errors was $-0.102(p=.064)$, with NA was $-0.318\left(p=4.088 \times 10^{-9}\right)$. The correlations indicated that when one variable increased, the other variable decreased. For example, when the students' number knowledge scores increased, the number of MC errors decreased.

\section{Division}

Data revealed that the correlation of the students' number knowledge scores with RAEe error types was $-0.104(p<$ $.10)$, while with NA was $-0.344\left(p=1.718 \times 10^{-10}\right)$ suggesting that when students' number knowledge scores increased, the number of RAFe and NA errors decreased.

\section{Errors on multiplication and division problems across age}

\section{Multiplication}

The number of multiplication errors varied by age. Data indicated that the average number of errors among the 58 nine-year-old Portuguese students was 2.24 (130/58) per student. The majority of the students $(n=226)$ were 10 years old and the average number of errors was 2.4 errors. Thirtyfour students were 11 years old and they made an average of 3.11 errors. The average number of errors for the seven 12 year-old students was 3.85. See Table 4 for number of errors by type and age on multiplication problems.

MC was the most common type of error among the Portuguese students when solving multiplication computation problems. The nine-year-old students made an average of 0.63 MC errors, whereas the 10-year-old students had about $0.82 \mathrm{MC}$ errors. The other two age groups of students had the following average number of MC errors per student (a) 1.23 for 11-year-old students and (b) 0.71 for 12-yearold students. The second most frequent type of error in multiplication was No Attempt (NA). The nine-year-old students did not attempt to solve the multiplication problems an average of 0.31 per student, while the 10 -year-old students left the problems unanswered an average of 0.41 . Among the 11-year-old students, the average was 1 unanswered problem per student, whereas the 12-year-old students had an average of 0.85 . Multiplication computation problems involving decimals (i.e., REAa) were the third most predominant error type. The average number of REAa

Table 4. Number of errors by age and type for multiplication and division.

Type of errors

\begin{tabular}{|c|c|c|c|c|c|c|c|c|c|c|c|c|c|c|c|c|c|c|c|c|}
\hline \multirow[b]{2}{*}{ Age } & \multicolumn{2}{|c|}{$\mathrm{MC}$} & \multicolumn{2}{|c|}{$\mathrm{FR}$} & \multicolumn{2}{|c|}{$\mathrm{CZ}$} & \multicolumn{2}{|c|}{ WO } & \multicolumn{2}{|c|}{ RAEa } & \multicolumn{2}{|c|}{ RAEb } & \multicolumn{2}{|c|}{ RAEc } & \multicolumn{2}{|c|}{ RAEd } & \multicolumn{2}{|c|}{ RAEe } & \multicolumn{2}{|c|}{ NA } \\
\hline & $M$ & D & $M$ & D & $M$ & D & $M$ & D & $M$ & D & $M$ & D & $M$ & D & $M$ & D & $M$ & D & $M$ & D \\
\hline 9 & 37 & 1 & 22 & - & 0 & - & - & 0 & 32 & 1 & 0 & - & 20 & 74 & 0 & - & 1 & 17 & 18 & 97 \\
\hline 10 & 185 & 13 & 60 & - & 4 & - & - & 1 & 102 & 2 & 1 & - & 75 & 303 & 12 & - & 11 & 67 & 94 & 297 \\
\hline 11 & 42 & 1 & 4 & - & 0 & - & - & 2 & 12 & 0 & 0 & - & 11 & 42 & 0 & - & 3 & 11 & 34 & 73 \\
\hline 12 & 5 & 0 & 4 & - & 1 & - & - & 0 & 4 & 0 & 0 & - & 7 & 9 & 0 & - & 0 & 4 & 6 & 14 \\
\hline 13 & 2 & 0 & 0 & - & 0 & - & - & 0 & 1 & 0 & 0 & - & 0 & 0 & 0 & - & 0 & 0 & 0 & 3 \\
\hline
\end{tabular}

Note: $\mathrm{MC}=$ miscalculation; $\mathrm{FR}=$ failure to regroup; $\mathrm{CZ}=$ concept of zero; $\mathrm{WO}=$ wrong operation; $\mathrm{RAEa}=$ random errors: decimals; $\mathrm{RAEb}=$ random errors: copying numbers incorrectly; RAEc = random errors: incorrect answer without explanation; RAEd=random errors: omission (began to solve the problem, but did not complete it); $\mathrm{RAEe}=$ random errors: procedure error; $\mathrm{NA}=$ no attempt to solve; $\mathrm{M}=$ multiplication; $\mathrm{D}=$ division. 
group 追 age 9 官 age 10 追 age 11 官 age 12

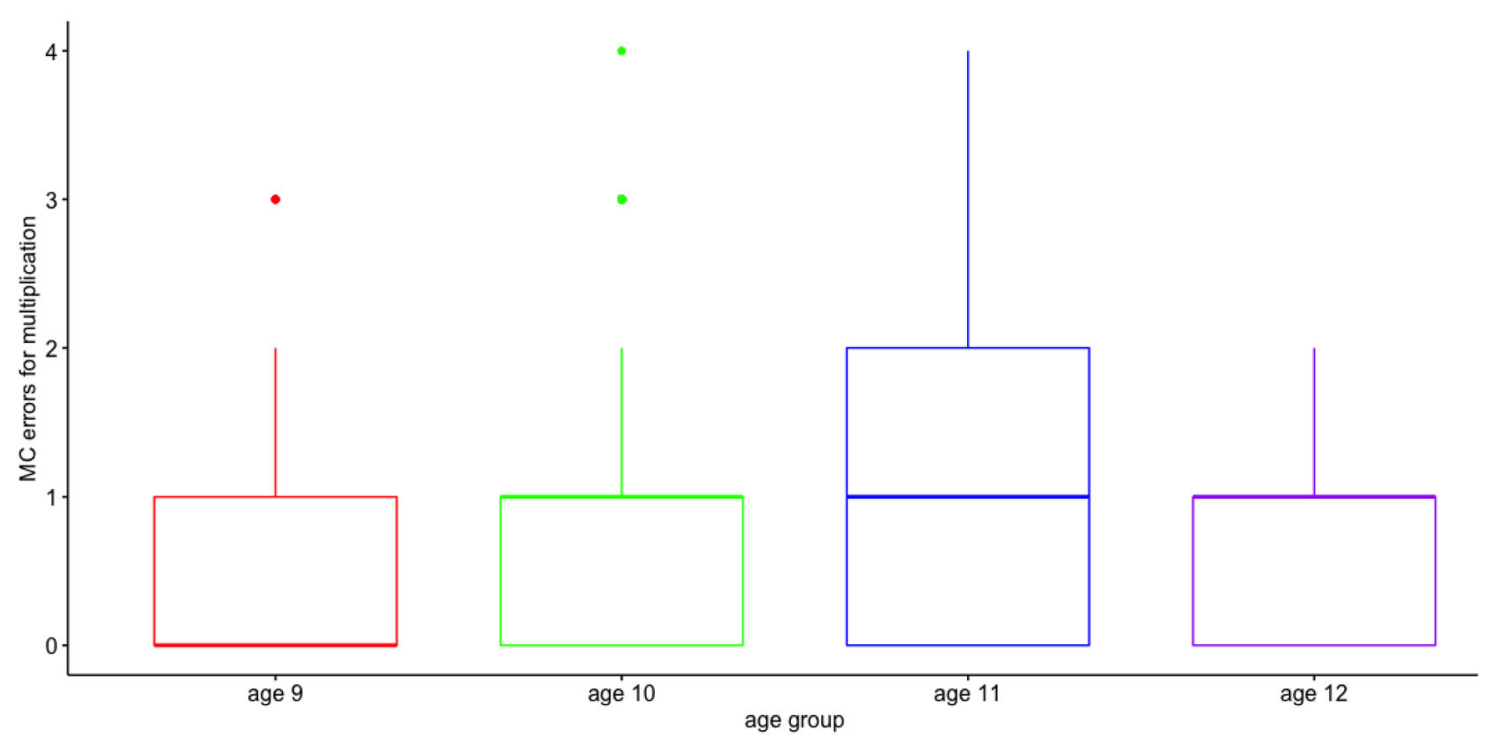

Figure 1. Miscalculation (MC) errors on multiplication problems across age.

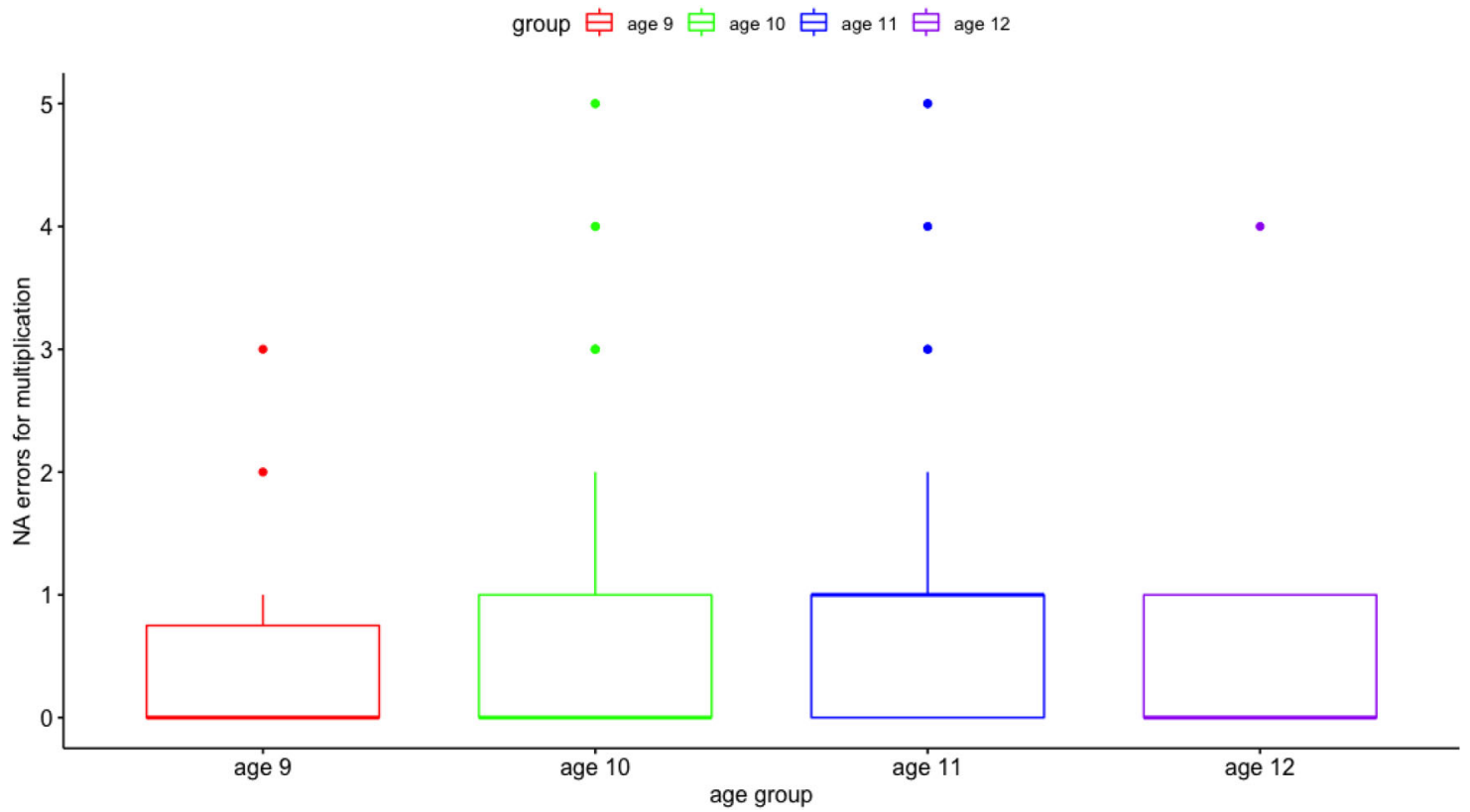

Figure 2. No attempt (NA) errors on multiplication problems across age.

error type for the nine-year-old students was 0.55 and for the 10-year-old students was 0.45 . The other two age groups (11 and 12) of students had an average of 0.35 and 0.57 .

Figures 1 and 2display the MC and NA errors on multiplication problems across age groups. The Kruskal-Wallis rank sum test revealed statistically-significant differences among age groups on both MC errors $\left(\chi^{2}=8.5227, p<.05\right)$ and NA errors on multiplication computation problems $\left(\chi^{2}=10.451, p\right.$ $<.05)$. For MC errors, the Dunn post-hoc analysis showed a statistically-significant difference between 9-year-old and 11year-old students $(z=2.912, p<.05)$ and between 10 -year-old and 11-year-old students $(z=-2.261, p<.05)$ on MC errors. These data suggest that 11-year-old students made more MC errors on multiplication computation problems compared to 9- year-old and 10-year-old students. For NA errors, the Dunn post-hoc analysis revealed a difference between 9-year-old students and 11-year old students $(z=2.951, p<.05)$ and between 10-year-old students and 11-year-old students $(z=$ -2.923, $p<.05)$ indicating that 11-year-old students made more NA errors on multiplication computation problems than 9-year-old and 10-year-old students.

\section{Division}

Table 4 displays the number of errors by type and age on division problems.

When solving division computation problems, the nineyear-old Portuguese students made an average of 3.27 errors 
per student. The 10-year-old students had an average of 3.02 errors, while the 11-year-old students made 3.79 errors per student when solving division computation problems. The seven 12-year-old students had an average of 3.85 errors. The majority of the Portuguese rising fifth graders did not attempt to solve the division computation problems. The mean of the NA error type amongst the two youngest groups of students was 1.67 and 1.31. The 11-year-old students averaged 2.14 (73/34), and the 12-year-old students had an average of $2 \mathrm{NA}$ error type per student. The second most identified type of division error was an incorrect answer without explanation (i.e., RAEc). The average number of RAFc varied across age categories: 1.27 for nine-year-old students; 1.34 for 10 year-old students; 1.23 for 11-year-old students; and 1.28 for 12-year-old students. There were many procedural types of errors. The nine- and the 10-year-old students had averages of 0.29 and 0.3 per student on procedural errors (i.e., RAFe). The 11- and 12-year-old students' averages were 0.32 and 0.57 . The Kruskal-Wallis rank sum test did not reveal any statistically-significant differences between the number of errors on division problems among age groups at a significance level of 5\% and, thus, we did not report these data.

\section{Discussion}

Our goal in this study was two-fold. First, we conducted an analysis of the types of error patterns in elementary-aged Portuguese students on multiplication and division computation problems. Second, we determined whether a correlation existed between students' performance on problems related to number knowledge and their performance on multiplication and division computation problems. Originally, we did not have a research question related to age. However, we examined if the number of errors on computation problems differed across students' age because of the wide spread of age differences among participants. Data revealed that few students mastered computation of multiplication and division problems at grade level.

\section{Implications of errors for instruction}

\section{Multiplication errors}

Miscalculation. Our data showed that MC error types were the most common errors on multiplication computation problems. The older participants enrolled in our study had higher averages of MC error types. This is not unexpected, since Portugal uses grade retention as a way of dealing with students' academic difficulties. Our findings are similar to other studies (Geary, 2011; Nelson \& Powell, 2018) that have identified math fact mastery and fluency and computation procedural difficulties as characteristics of students with math difficulties. Although we do not have data to support this assumption, it is possible that the older students had a learning disability in math and were retained in the same grade level one or more times.

Without error pattern analysis of students' responses, teachers could not provide effective remediation or corrective instruction to address the students' systematic errors.
Consequently, students would continue to make the same errors because the incorrect concepts or procedures were not being addressed through instruction (Ashlock, 2010). Thus, the lack of specialized instruction to remediate the students' systematic errors not only negatively affected the students' acquisition and fluency of math computation skills, but also adversely affected their further learning as illustrated by a larger number of errors of the older students compared to the younger ones. Indeed, researchers have documented that many students have difficulties acquiring basic math skills, such as counting, place value, recalling arithmetic facts, and computation of whole numbers and fail to achieve fluency (Geary, 2011; Jordan et al., 2010; Namkung \& Fuchs, 2012). Accordingly, it is important that teachers incorporate daily fluency practice into their instruction.

No attempt or answers without explanation. Because math concepts and skills follow a sequential and gradual sequence, students who have not achieved fluency on arithmetic facts are more likely to encounter difficulties solving multiplication and division computation problems. The results of this study indicated that, besides MC error types $(n=271)$, errors involving multiplication of decimals comprised the greatest numbers of error types $(n=151)$. Data also showed that some students $(n=152)$ did not even attempt to solve some of the multiplication computation problems suggesting they did not know how to begin solving the problems. The number of incorrect answers without an explanation also was large $(n=113)$ suggesting that, in those cases where students tried to solve the computation problems, they did not know what to do, their answers were unreasonable, and they did not follow any logical procedure or explanation. Therefore, classroom instruction needs to address students' lack of conceptual understanding of decimals. Using the concrete-representational-abstract sequence, teachers should start explicit instruction with the use of manipulatives (e.g., base ten blocks) to review the concept of place value and the understanding of multiplication by showing that a whole can be composed from equal-sized groups. Starting with whole numbers, students can build their arrays. Then, the teacher should develop the concept of decimal number sense. Graph paper or number lines also are helpful for teaching decimal concepts. Once the students grasp the concept, multiplication of decimals should be introduced with simple problems, such as a whole number factor by tenths (e.g., $5 \times 0.3)$ and hundredths which can be represented with base-ten blocks (Cathcart et al., 2011).

Multiplication is a complex operation and it includes many rules. Students seem to not fully understand the logic of multiplication and they often become confused with the procedural rules for multiplying two or more digits. Yorulmaz and Önal (2017) explained that students memorize the rules of operations without understanding them. Furthermore, students are not given enough opportunities to practice the skills learned and receive correct feedback. The multiplication computation problems become even more difficult when decimals are included in the calculation. 
For example, some features of decimal arithmetic procedures are related to the placement of decimal point. Students who do not understand the rationale for the decimal point or have misconceptions about decimals due to the lack of conceptual understanding (e.g., decimal numbers versus cardinal numbers, place value) are more likely to have difficulties when completing multiplication problems (Mehmetlioglu, 2014). When students learn procedures without understanding them, they are less likely to remember them, and when teachers do not have conceptual knowledge of math concepts, they cannot communicate the topic effectively and address students' questions and misconceptions (LortieForgues et al., 2015). Therefore, instruction should be geared toward conceptual knowledge.

\section{Division}

No attempt or answer without explanation. Similar to the findings on multiplication computation problems, the two most common division error types identified seemed to be due to students not knowing or not understanding the procedures to solve division computation problems. Specifically, $47 \%$ of errors were coded as NA, indicating that the students did not try to solve the division computation problems. When students attempted to solve the division problems, their answers were unreasonable. In other words, they did not know the concept of division or did not comprehend the procedures required to solve the division computation problems. Furthermore, data revealed that a larger number of students had more difficulties completing division problems than multiplication problems. This finding is consistent with the fact that division is considered to be the most difficult of the four arithmetic operations and it requires many prerequisite skills (Cathcart et al., 2011).

Instruction on division computation should focus on instilling an understanding of the concept of division, knowing the basic facts in addition to efficiently be able to multiply and subtract. Explicit instruction using base-ten blocks can assist students understand the meaning of division. Students must achieve mastery at the concrete, representational or drawing, and the abstract levels of understanding before introducing division with remainders. Students need to practice solving several problems to become proficient at computation, especially division (Cathcart et al., 2011). Stefanich and Rokusek (1992), who analyzed fourth-graders' computational error types on division computation problems, suggested that those students who do not have a good concept of place value tend to give unreasonable answers because they do not have a frame of reference.

\section{Correlation: Implications for instruction}

Because the findings of our study confirmed Stefanich and Rokusek (1992) assertion regarding the concept of place value, we decided to examine if there were any correlations between the students' number knowledge scores and their performance in solving multiplication and division computation problems. Data showed a negative correlation between number knowledge and multiplication and division computation problems. This suggested that those students who obtained higher scores on number knowledge had less errors when solving multiplication and division computation problems. This finding is consistent with previous studies (Jordan et al., 2010; Skagerlund \& Traff, 2014) that have shown that number knowledge predicts elementary students' math difficulties. This becomes diagnostically significant regarding teacher instruction. That is, students need to first acquire concepts related to number knowledge (e.g., symbolic number sense, magnitude), and then understand the concept of place value, multiplication, and division in addition to receiving explicit instruction on the procedures used to solve multiplication and division problems. It is critical that students master basic computation skills to be able to use and understand higher math skills (Ashlock, 2010).

\section{Errors on multiplication and division problems across age: Implications for instruction}

In the present study, some of the participants were older than the average age of fourth graders who usually are nine to ten years old. Specifically, there were 34 students who were 11 years old, seven students who were 12 years old, and one student who was 13 years old. When the researchers asked the teachers to provide an explanation related to students' age, they indicated that the students had been retained in at least one grade because they had not learned the skills to move on to the next grade level. This suggests that it is critical to design and provide struggling students intensive intervention targeting the specific problematic areas to promote skill acquisition and fluency as soon as possible. Using an effective assessment-based intervention has the potential to promote student academic success while avoiding stigmatization experienced by students when asked to repeat a grade level several times due to lack of progress.

Another important result is that our data support the idea that without specialized intervention based on an analysis of error patterns, students will continue to make the same errors and fall behind their peers. Specifically, results indicated that 11-year-old students made more MC and NA errors on multiplication computation problems compared to younger students and, thus, suggesting the only repeated exposure to the same content is insufficient for acquisition of math computation. For students to acquire conceptual and procedural knowledge, teachers must have a good understanding of math concepts and be able to explain to their students the procedures required to solve a computation problem (Thanheiser, 2012).

At present, too few teachers are adequately prepared to design and implement interventions based on their students' errors (Cooper, 2009). For instance, Riccomini (2005) examined teachers' ability to identify students' systematic error patterns in subtraction. Data analysis showed that teachers were able to identify the students' error patterns, but they did not use the detected error patterns to provide remediation instruction. This finding is important because to teach students about math concepts, teachers must have 
Table 5. Recommended instructional strategies to address the most common multiplication errors.

\begin{tabular}{|c|c|c|c|}
\hline Error & Error cause & Recommended instructional strategies & Examples and resources \\
\hline \multirow[t]{8}{*}{ Miscalculation } & Lack of facts fluency & $\begin{array}{l}\text { Teach explicitly basic fact rules } \\
\text { and strategies }\end{array}$ & $\begin{array}{l}\text { The } 0 \text { Rule : any number times zero } \\
\text { equals zero }\end{array}$ \\
\hline & $\begin{array}{l}\text { Inefficient and } \\
\text { inaccurate computing }\end{array}$ & $\begin{array}{l}\text { Implement daily } 1-2 \text { min. fluency } \\
\text { practice with corrective feedback }\end{array}$ & $\begin{array}{l}\text { Nines pattern: next product is one more } \\
\text { ten, and one less unit }(5 \times 9=45 \text {, so } \\
6 \times 9=54)\end{array}$ \\
\hline & Work memory deficit & $\begin{array}{l}\text { Provide opportunities for varied and } \\
\text { motivating practice }\end{array}$ & Same factors: $5 \times 6=30$, so $6 \times 5=30$ \\
\hline & $\begin{array}{l}\text { Difficulty retrieving information } \\
\text { from long-term memory } \\
\text { Lack of conceptual }\end{array}$ & $\begin{array}{l}\text { Use calculator for immediate feedback } \\
\text { Teach the concept of multiplication } \\
\text { through word problems }\end{array}$ & $\begin{array}{l}\text { Games and motivating activities for } \\
\text { practice (e.g., computer } \\
\text {-based practice) }\end{array}$ \\
\hline & understanding & & $\begin{array}{l}\text { Constant time-delay technique } \\
\text { Copy-cover-compare drills }\end{array}$ \\
\hline & & & $\begin{array}{l}\text { Use mnemonic and pictures (See Wood } \\
\text { \& Frank, } 2000 \text { for multiplication } \\
\text { strategy charts) }\end{array}$ \\
\hline & & & $\begin{array}{l}\text { The Strategic Math Series (Mercer \& } \\
\quad \text { Miller, 1991-1994) }\end{array}$ \\
\hline & & & $\begin{array}{l}\text { Touch Math (Bullock, 1975): multisensory } \\
\text { approach (https://www2.touchmath. } \\
\text { com/) }\end{array}$ \\
\hline \multirow[t]{6}{*}{ Failure to regroup } & $\begin{array}{l}\text { Lack of conceptual knowledge } \\
\text { of place value } \\
\text { Lack of } \\
\text { procedural knowledge }\end{array}$ & $\begin{array}{l}\text { Use the Concrete-Representational- } \\
\text { Abstract (CRA) strategy to develop } \\
\text { conceptual knowledge }\end{array}$ & $\begin{array}{l}\text { Base-ten blocks for students to see the } \\
\text { connections between the concrete } \\
\text { representation, the place value, and } \\
\text { the algorithm }\end{array}$ \\
\hline & Visual-spatial deficit & $\begin{array}{l}\text { Use explicit instruction with teacher } \\
\text { modeling and multiple opportunities } \\
\text { for students to practice }\end{array}$ & $\begin{array}{l}\text { Use mnemonics, such as MAMA strategy } \\
\text { (Multiply, Across, Multiply, Add) to } \\
\text { help students with the } \\
\text { procedural steps }\end{array}$ \\
\hline & Working memory deficit & Teach strategies to teach procedure & $\begin{array}{l}\text { Use the Strategic Math Series } \\
\text { (Multiplication with regrouping) }\end{array}$ \\
\hline & & $\begin{array}{l}\text { Have students verbalize their thinking } \\
\text { and scaffold the procedure }\end{array}$ & \\
\hline & & Use real-life word problems & \\
\hline & & $\begin{array}{l}\text { Use graph paper to assist those who } \\
\text { have visual-spatial difficulties }\end{array}$ & \\
\hline \multirow[t]{8}{*}{$\begin{array}{l}\text { Multiplication } \\
\text { of decimals }\end{array}$} & $\begin{array}{l}\text { Difficulty with place value and } \\
\text { number sense }\end{array}$ & $\begin{array}{l}\text { Teach the concept of place value and its } \\
\text { relationship to multiplication }\end{array}$ & Base-ten blocks \\
\hline & Difficulty with working memory & Explain the purpose of decimals & Grids and other drawings \\
\hline & & Link fractions and decimals & Number line \\
\hline & & Use explicit instruction and the & Money to help students see the \\
\hline & & Show examples and non-examples & \\
\hline & & Use games for practice & \\
\hline & & Use word problems & \\
\hline & & Ask students to explain their reasoning & \\
\hline \multirow{5}{*}{$\begin{array}{l}\text { Incorrect answer } \\
\text { without } \\
\text { explanation }\end{array}$} & $\begin{array}{l}\text { Lack of concept and } \\
\text { procedural knowledge }\end{array}$ & $\begin{array}{l}\text { Provide explicit instruction on concept } \\
\text { and procedural knowledge of }\end{array}$ & Base-ten blocks or other manipulatives \\
\hline & Working memory deficits & multiplication computation & Build models and draw pictures \\
\hline & Lack of reasoning & Use the CRA strategy & Games and motivating activities for \\
\hline & $\begin{array}{l}\text { Inhibition of irrelevant } \\
\text { information }\end{array}$ & Ask students to explain their reasoning & practicing multiplication facts \\
\hline & $\begin{array}{l}\text { Lack of fluency on } \\
\text { multiplication facts }\end{array}$ & $\begin{array}{l}\text { Pinpoint the student's specific difficulties } \\
\text { to provide remedial instruction } \\
\text { Review place value concept }\end{array}$ & \\
\hline
\end{tabular}

mathematical knowledge and the ability to explain those concepts to their students (Thanheiser, 2009). It becomes important that these skills are incorporated into pre-service and professional development programs.

\section{Limitations}

Several limitations should be considered when interpreting the findings of this study. First, the data are based on participants from a single geographic area (i.e., northern region of Portugal). Therefore, data reported in this study are representative only of the students and schools selected for participation in this study. Second, the assessment was administered at the beginning of the year when students started attending fifth grade. The timing of the assessment was due to delays in obtaining the university's approval and schools' agreement. Research conducting future studies on this topic should consider administering the assessment at the end of June when students would have completed their fourth grade instead of at the beginning of September when they would start their fifth grade. Third, the small subset of item per computation skills (i.e., 10 items) may have influenced the results. Specifically, the small number of items may have skewed the results of the analysis, and thus, lead to inaccurate conclusions. Fourth, because Portugal does not have special education services for students with learning disabilities, we do not know if the older students and the 
Table 6. Recommended instructional strategies to address the most common division errors.

\begin{tabular}{|c|c|c|c|}
\hline Error & Error cause & Recommended instructional strategies & Example \\
\hline \multirow[t]{5}{*}{$\begin{array}{l}\text { Incorrect answer } \\
\text { without explanation }\end{array}$} & $\begin{array}{l}\text { Lack of concept and } \\
\text { procedural knowledge }\end{array}$ & $\begin{array}{l}\text { Provide explicit instruction on } \\
\text { concept and procedural } \\
\text { knowledge of division } \\
\text { computation }\end{array}$ & $\begin{array}{l}\text { Base-ten blocks or other } \\
\text { manipulatives (Use an array to } \\
\text { solve a division problem) }\end{array}$ \\
\hline & Working memory deficits & Use the CRA strategy & Build models and draw pictures \\
\hline & Inhibition of irrelevant information & $\begin{array}{l}\text { Ask students to explain } \\
\text { their reasoning }\end{array}$ & Modeling and guided practice \\
\hline & $\begin{array}{l}\text { Lack of fluency on multiplication and } \\
\text { division facts }\end{array}$ & Review place value & $\begin{array}{l}\text { Games and motivating activities for } \\
\text { practicing facts }\end{array}$ \\
\hline & $\begin{array}{l}\text { Reasoning problems } \\
\text { Memory difficulties }\end{array}$ & $\begin{array}{l}\text { Pinpoint the student's specific } \\
\text { difficulties to provide remedial } \\
\text { instruction. }\end{array}$ & Opportunities for practice \\
\hline \multirow[t]{3}{*}{$\begin{array}{l}\text { No attempt to solve } \\
\text { the problem }\end{array}$} & $\begin{array}{l}\text { Lack of conceptual and } \\
\text { procedure knowledge }\end{array}$ & $\begin{array}{l}\text { Explicitly teach the concept } \\
\text { of division }\end{array}$ & Provide examples and nonexamples \\
\hline & Working memory deficits & Link division to multiplication & Use the CRA model \\
\hline & Poor-decision-making & $\begin{array}{l}\text { Review subtraction and place value } \\
\text { Model procedure }\end{array}$ & Guided practice \\
\hline
\end{tabular}

students who performed poorly on multiplication and division computation tasks had a disability.

\section{Implications for future research}

Future research needs to focus on developing protocols for in-service and preservice teachers to perform error analysis of their students' computation skills and identify if those errors are related to procedural or conceptual knowledge. Another area of future research that should be explored consists of computation of multidigit numbers. Data from the current study and previous studies (Nelson \& Powell, 2018; Thanheiser, 2012) showed that students consistently have difficulties solving multidigit computation problems. Error patterns involving computation of multidigit algorithms often are related to place value. Future research should examine the error patterns students make when solving multidigit computation problems and conduct studies to examine the effects of the intervention on increasing students' performance.

\section{Implications for practice}

The results of this study also have implications for practitioners and teacher education programs. The importance of error analysis is evident. Error analysis provides a diagnostic and instructional basis for teachers to address individual student's difficulties by targeting specific concepts and skills. Data collected and analyzed through error analysis also are critical to student progress monitoring. By becoming aware of students' misconceptions and problematic areas, teachers can differentiate instruction and develop lessons to attend to those diagnostic areas that require more intensive intervention. Instruction that focuses on an individual student's error patterns is likely to improve that student's math achievement. Students must master knowing about math (i.e., conceptual knowledge) and doing math (i.e., procedural knowledge) to be able to have a continuous and steady performance in math (Foley \& Cawley, 2003).

The importance of conducting an error analysis to identify error patterns and possible causes has been emphasized in the literature. For example, error patterns have been associated with lack of conceptual knowledge (i.e., knowing about math), procedural knowledge (i.e., doing math), and erroneous math concepts (Foley \& Cawley, 2003). Several researchers have argued that error patterns are due not only to students' characteristics (e.g., inattention, memory problems), but also to instructional factors, such as pace of instruction, too few student opportunities to practice, and lack of teacher corrective feedback (Nelson \& Powell, 2018). Tables 5 and 6 display the most frequent multiplication and division errors and recommended strategies to address these errors and improve students' math performance.

\section{Conclusion}

Systematic errors often are the result of students' misconception, although they also can be related to procedural knowledge. Usually, when students struggle in math, it is because they need to be taught how to construct meaning for the algorithms instead of being drilled on procedures (Thanheiser, 2012). Researchers who have examined students' error patterns in fractions also have concluded that students' errors often are linked to concept misunderstandings (Aksoy \& Yazlik, 2017). Thus, if students' errors are not remediated, students will continue to difficulties learning the content presented and will struggle to acquire higherorder math concepts and skills. Regrettably, many pre-service and in-service math teachers do not have the knowledge of how to conduct an error analysis of students' responses, do not know how to remediate error patterns, or have misconceptions similar to their students' misconceptions.

The results of this study have important implications for practitioners. First, teachers must analyze their students' incorrect answers to determine whether students are making careless mistakes or conceptual or procedural errors. Second, teachers must decide whether an error pattern exists or if it is a one time mistake. This will require student progress monitoring. Teachers will need to create a system to systematically examine and document students' responses. Third, they must design instruction based on students' error patterns. If students' errors are not addressed, students will continue making the same errors as shown in our results. Another implication for practitioners is the need to build on 
the understanding of the four operations. A student needs to have conceptual knowledge to learn the procedures of computation because conceptual and procedural knowledge are interrelated (Arslan, 2010; Cathcart et al., 2011). Additionally, teachers need to plan for various opportunities for students to practice the skill and receive correct feedback as soon as possible. Criterion for mastery must be established. Because we know that computation is the foundation for more complex math skills, students must master computation skills across the elementary grades (Ashlock, 2010).

\section{Disclosure statement}

There are no potential conflicts of interest with respect of the research, authorship, and/or publication of this article.

\section{Funding}

This research was sponsored by a research award to the second author from the Fulbright U.S. Scholar Program.

\section{Notes on contributors}

Dr. Lucia M. Tabacu is an associate professor of statistics at Old Dominion University.

Dr. Silvana M. R. Watson is a professor of special education at Old Dominion University.

Dr. Laura C. Chezan is an associate professor of special education at Old Dominion University.

Dr. Robert Gable is an emminent professor of special education at Old Dominion University.

Dr. Célia R. Oliveira is an associate professor of psychology at the Universidade Lusófona de Porto, Portugal.

Dr. João Lopes is a professor of psychology at the Universidade de Minho, Porto, Portugal.

\section{ORCID}

João Lopes (D) http://orcid.org/0000-0001-5005-120X

\section{References}

Aksoy, N. C., \& Yazlik, D. O. (2017). Student errors in fractions and possible causes of these errors. Journal of Education and Training Studies, 5(11), 219-233. https://doi.org/10.11114/jets.v5i11.2679

Arslan, S. (2010). Traditional instruction of differential equations and conceptual learning. Teaching Mathematics and Its Applications, 29(2), 94-107. https://doi.org/10.1093/teamat/hrq001

Ashlock, R. B. (2010). Errors patterns in computation: Using error patterns to help each student learn (10th ed.). Allyn \& Bacon.

Benjamini, Y., \& Hochberg, Y. (1995). Controlling the false discovery: A practical and powerful approach to multiple testing. Journal of the Royal Statistical Society: Series B (Methodological), 57(1), 289-300. https://doi.org/10.1111/j.2517-6161.1995.tb02031.x

Brown, J. S., \& Burton, R. R. (1978). Diagnostic models for procedural bugs in basic mathematical skills. Cognitive Science, 2(2), 155-192. https://doi.org/10.1016/S0364-0213(78)80004-4

Callejo, M. L., \& Zapatera, A. (2017). Prospective primary teachers' noticing of students' understanding of pattern generalization.
Journal of Mathematics Teacher Education, 20(4), 309-333. https:// doi.org/10.1007/s10857-016-9343-1

Cathcart, W. G., Pothier, Y. M., Vance, J. H., \& Bezuk, N. S. (2011). Learning mathematics in elementary and middle schools: A learnercentered approach (5th ed.). Pearson.

Cebulski, L. (1984). Children's errors in subtraction: An investigation into causes and remediation. Report Research/Technical, 143, $27 \mathrm{p}$.

Cooper, S. (2009). Preservice teachers' analysis of children's work to make instructional decisions. School Science and Mathematics, 109(6), 355-362. https://doi.org/10.1111/j.1949-8594.2009.tb18105.x

Dunn, O. J. (1964). Multiple comparisons using rank sums. Technometrics, 6(3), 241-252. https://doi.org/10.1080/00401706.1964. 10490181

Engelhardt, J. M. (1977). Analysis of children computational errors: A qualitative approach. British Journal of Educational Psychology, 47(2), 149-154. 8279.1977.tb02340.x https://doi.org/10.1111/j.2044-

Foley, T. E., \& Cawley, J. F. (2003). About the mathematics of division: Implications for students with disabilities. Exceptionality, 11(3), 131-149. https://doi.org/10.1207/S15327035EX1103_02

Geary, D. C. (2011). Cognitive predictors of achievement growth in mathematics: A 5-year longitudinal study. Developmental Psychology, 47(6), 1539-1552. https://doi.org/10.1037/a0025510

Gojak, L. M. (2012, November 1). Fluency: Simply fast and accurate? I think not! NCTM Summing Up. https://www.nctm.org/News-andCalendar/Messages-from-the-President/Archive/Linda-M_-Gojak/ Fluency_-Simply-Fast-and-Accurate_-I-Think-Not!/

Higgins, J. J. (2004). Introduction to modern nonparametric statistic. Thompson Brooks/Cole.

Jordan, N. C., Glutting, J., \& Ramineni, C. (2010). The importance of number sense to mathematics achievement in first and third grades. Learning and Individual Differences, 20(2), 82-88. https://doi.org/10. 1016/j.lindif.2009.07.004

Jordan, N. C., Hanich, L. B., \& Kaplan, D. (2003). A longitudinal study of mathematical competencies in children with specific mathematics difficulties versus children with comorbid mathematics and reading difficulties. Child Development, 74(3), 834-850. https://doi.org/10. $1111 / 1467-8624.00571$

Lopes, J., \& Bueno, M. (2014). Construção e validação de uma prova de mathemática para alunos do primeiro ao quarto ano de escolaridade [Development and validation of a math test for first to fourth grade students]. Psicologia: Reflexão e Crítica, 27(3), 434-442. https://doi.org/10.1590/1678-7153.201427303

Lortie-Forgues, H., Tian, J., \& Siegler, R. S. (2015). Why is learning fraction and decimal so difficult? Developmental Review, 38, 201-221. https://doi.org/10.1016/j.dr.2015.07.008

Mehmetlioglu, D. (2014). Misconceptions of elementary school students about comparing decimals numbers. Procedia - Social and Behavioral Sciences, 152, 569-574. https://doi.org/doi: https://doi. org/10.1016/j.sbspro.2014.09.245

Mercer, C. D., \& Miller, S. P. (1991-1994). The strategic math series. Edge Enterprises.

Namkung, J. M., \& Fuchs, L. S. (2012). Early numerical competencies of students with different forms of mathematics disabilities. Learning Disabilities Research \& Practice, 27(1), 2-11. https://doi. org/10.1111/j.1540-5826.2011.00350.x

National Mathematics Advisory Council. (2008). Foundations for success. The final report of the National Mathematics Advisory Panel. U.S. Department of Education.

Nelson, G., \& Powell, S. R. (2018). Computation error analysis: Students with mathematics difficulty compared to typically achieving students. Assessment for Effective Intervention, 43(3), 144-156. https://doi.org/10.1177/1534508417745627

Ogle, D. H., Wheeler, P., \& Dino, A. (2018). FSA: Fisheries stock analysis ( $\mathrm{R}$ package Version 0.8.22.9000 Retrieved from https://github. com/droglenc/FSA.

R Core Team. (2017). R: A language and environment for statistical computing. R Foundation for Statistical Computing. https://www.Rproject.org/ 
Riccomini, P. J. (2005). Identification and remediation of systematic error patterns in subtraction. Learning Disability Quarterly, 28(3), 233-242. https://doi.org/10.2307/1593661

Roberts, G. H. (1968). The failure strategies of third grade arithmetic pupils. The Arithmetic Teachers, 15, 442-446. http://www.jstor.org/ stable/41185806

Sapire, I., Shalem, Y., Wilson-Thompson, B., \& Paulsen, R. (2016). Engaging with learners' errors when teaching mathematics. PythagorasJournal of the Association for Mathematics Education of South Africa, 37, 1012-2346. https://doi.org/10.4102/Pythagoras.v37i1.331

Skagerlund, K., \& Traff, U. (2014). Development of magnitude processing in children with developmental dyscalculia: Space, time, and number. Frontiers in Psychology, 5, 675-615. https://doi.org/10.3389/ fpsyg.2014.00675

Skwarchuk, S.-L., \& Betts, P. (2006). An error analysis of elementary school children's number production abilities. Australian Journal of Educational \& Developmental Psychology, 6, 1-11. http://newcastle. edu.au/group/ajedp/

Stefanich, G. P., \& Rokusek, T. (1992). An analysis of computational errors in the use of division algorithms by fourth-grade students. School Science and Mathematics, 92(4), 201-205. https://doi.org/10. 1111/j.1949-8594.1992.tb12173.x

Thanheiser, E. (2009). Preservice elementary school teachers' conceptions of multidigit whole numbers. Journal for Research in Mathematics Education, 40, 251-281. http://www.jstor.org/stable/ 40539337
Thanheiser, E. (2012). Understanding multidigit whole numbers: The role of knowledge components connections, and context in understanding regrouping 3 +- digit numbers. The Journal of Mathematical Behavior, 31(2), 220-234. https://doi.org/10.1016/j. jmathb.2011.12.007

Tolar, T. D., Lederberg, A. R., \& Fletcher, J. M. (2009). A structural model of algebra achievement: Computational fluency and spatial visualization as mediators of the effect of working memory on algebra achievement. Educational Psychology, 29(2), 239-266. https://doi. org $/ 10.1080 / 01443410802708903$

Traff, U., \& Samuelson, J. (2013). Analysis of errors in multi-digit arithmetic and arithmetic word problem solving in children with mathematics learning difficulties. Special Education, 1, 121-132.

Wood, D. K., \& Frank, A. R. (2000). Memory-enhancing strategies to learn multiplication facts. Teaching Exceptional Children, 32(5), 78-82. https://doi.org/10.1177/004005990003200511

Yorulmaz, A., \& Önal, H. (2017). Examination of the views of class teachers regarding the errors primary school students make in four operations. Universal Journal of Educational Research, 5(11), 1885-1895. https://doi.org/10.13189/ujer.2017.051105

Zhang, D., Ding, Y., Barrett, E. D., Xin, Y. P., \& Liu, R. (2014). A comparison of strategic development of multiplication skills in lowachieving, average achieving, and high achieving students. European Journal of Psychology of Education, 29(2), 195-214. https://doi.org/ 10.1007/s10212-013-0194-1 